[Agr. Biol. Chem., Vol. 36, No. 6, p. $1081 \sim 1084,1972$ ]

\title{
A New Enzyme Species of $p$-Hydroxybenzoate Hydroxylase during Oxygenating Process Observed by the Stopped-flow Method ${ }^{\dagger}$
}

Sir:

The reaction mechanism of $p$-hydroxybenzoate hydroxylase (EC 1.14.1.12) from Pseudomonas desmolytica IAM 1123, FAD containing monooxygenase," consists of three sequential reaction steps and each elementary reaction can be observed independently by separate addition of three substrates, i.e., $p$-HBA, NADPH, and $\mathrm{O}_{2}{ }^{2 \sim 41}$ From the kinetical data, we proposed that an oxygenated intermediate, a reduced flavin-oxygen enzyme complex, is included in this enzyme reaction as one of the rate limiting intermediate.

In this communication, the oxygenation step was observed more precisely by a stoppedflow apparatus. A new enzyme species appeared at the presteady state during the oxygenation of the fully reduced enzyme-substrate complex. This enzyme species was indicated to be a ternary complex of enzyme, substrate $\left(p\right.$-HBA) and $\mathrm{O}_{2}$.

Enzyme purification methods had been described previously. ${ }^{1 /}$ All measurements were made at $25^{\circ} \mathrm{C}$ in $0.05 \mathrm{M}$ phosphate buffer, $\mathrm{pH}$ 8.2. Absorption spectra were measured by a Hitachi recording spectrophotometer model 124. Time course of transmittance changes caused by the oxidation of the reduced enzymesubstrate complex was measured by a ChanceLegallais type flow apparatus ${ }^{5}$ attached with a San-ei oscillograph, model 101, as previously reported." Under anaerobic conditions, the solution containing a known amount of $p$-HBA

$\uparrow$ This investigation was supported by the Scientific Research Fund from the Ministry of Education of Japan.

Abbreviation: $p$-hydroxybenzoic acid; $p$-HBA. and the enzyme previously rejuced by an excess amount of NADPH was mixed with an equal volume of buffer containing different concentrations of oxygen $(130 \sim 1000 \mu \mathrm{M})$. A typical absorbance change at $450 \mathrm{~mm}$ is shown in Fig. $1-\mathrm{A}$. An initial rapid increase in absorbance at the reaction initiated (mixed-a, $t_{2}=2.5 \mathrm{msec}^{*}$ ) was followed by a slight increase

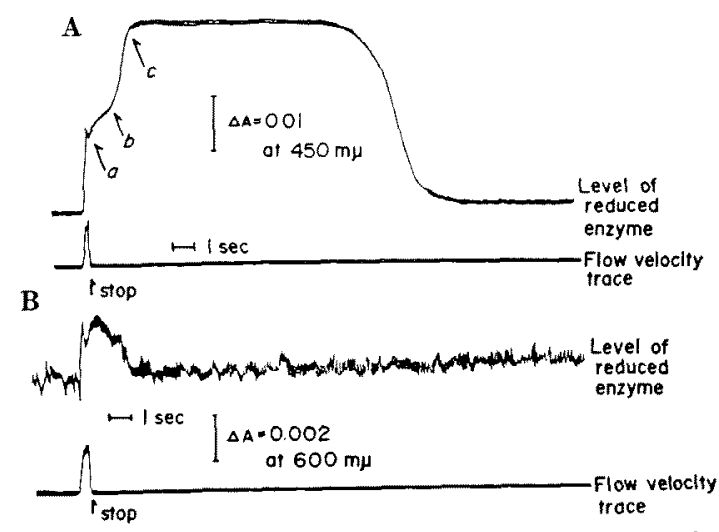

Fig. 1. Stopped-flow Traces for the Reaction of Oxygenatian Step by $p$-Hydroxybenzoate Hydroxylase.

The enzyme solution $\left(\mathrm{E}_{\mathrm{OX}}: 5.7 \mu \mathrm{M}\right.$ with respect to FAD) containing $p$-hydroxybenzoate $(286 \mu \mathrm{M})$ was fully reduced with an excess amount of NADPH $(856 \mu \mathrm{M})$ under anaerobic conditions. This solution was mixed with an equal volume of the buffer solution (0.05 M phophate buffer, pH 8.2) containing oxygen $(450 \mu \mathrm{M})$. Transmittance changes at $450 \mathrm{~nm}$ (upper curve, A) and $600 \mathrm{~nm}$ (lower curve, B) due to the reaction were followed by a stopped-flow apparatus. All concentrations were the final values.

* This was determined by separate traces with scaning speeds of 2 and $5 \mathrm{msec}$ per division of oscilloscope using a Yanaco stopped-flow and a Union Giken stopped-flow apparatus. 
(a-b) and subsequently by an increase (b-c) which reached a steady state 1 sec after mixing. After the dissolved oxygen had been consumed, the absorbance decreased to a fully reduced level by an excess amount of NADPH. The rapidly appearing inflection in absorbance change at $450 \mathrm{~nm}$ was observed more clearly when the concentration of oxygen increased. On the other hand, a weak absorption around $550 \sim 700 \mathrm{~nm}$ appeared concomitantly with the increase at $450 \mathrm{~nm}$ and diminished within $1 \mathrm{sec}$ after the flow stopped. A typical trace at $600 \mathrm{~nm}$ is shown in Fig. 1-B. The absorbance at $600 \mathrm{~nm}$ increased so rapidly as the increase at $450 \mathrm{~nm}$ (Fig. 1-A, - a) and then decreased. Both rapidly appearing signals might be due to the same transient enzyme species, since the behavior of absorbance at $600 \mathrm{~nm}$ corresponded to the presteady state observed by the absorbance change at $450 \mathrm{~nm}$. The velocity of the absorbance increase at $600 \mathrm{~nm}$ was about $170 \mathrm{sec}^{-1 *}$ (pseudo-first order reaction constant), which is rapid enough to explain the overall maximal velocity per enzyme $\left(V_{\max } / \mathrm{e}=72\right.$ $\left.\sec ^{-1}\right)$. Hence, this enzyme species could be included in the overall reaction. In the presence of the substrate analogs (benzoate, 2,4dihydroxybenzoate and protocatechuate (product)), such a transient enzyme species could not be detected. Without $p-\mathrm{HBA}$, neither of an inflection on absorbance changes at $450 \mathrm{~nm}$ or absorbance changes at a longer wavelength could be observed.

Two series of kinetic experiments concerning this transient enzyme species were made by using the flow apparatus at $600 \mathrm{~nm}$, since both oxidized and fully reduced FAD moiety have no absorbance at this region. Firstly, a known amount of fully reduced enzyme-substrate solutions $\left(\mathrm{E}_{3 \mathrm{x}}: 13.6 \mu \mathrm{M}, \mathrm{S}: 572 \mu \mathrm{M}, \mathrm{NADPH}\right.$ : $950 \mu \mathrm{M})$ were mixed with an equal volume of the buffer solution containing various concentrations of oxygen $(130 \sim 1000 \mu \mathrm{M})$. Secondly, only the concentration of $p$-HBA was varied (S: $57.2 \sim 572 \mu \mathrm{M}, \mathrm{O}_{2}: 1240 \mu \mathrm{M}$ ). The results are shown in Fig. 2-A, B. The height of the peak

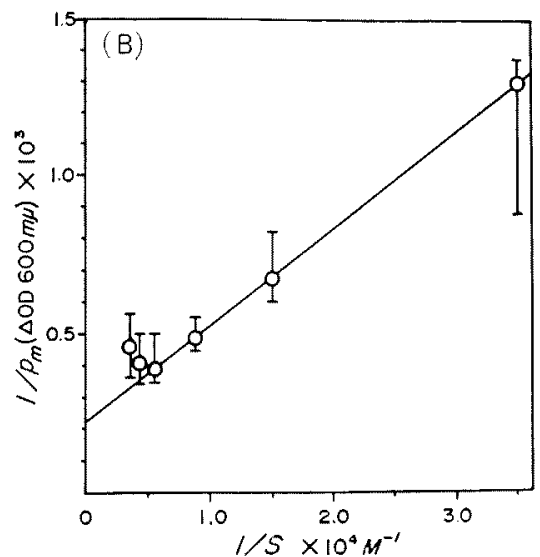

F1G. 2. Effects of the Concentrations of Oxygen and Substrate on the Transient Enzyme Species during the Presteady State of Oxygenating Step by $p$-Hydroxybenzoate Hydroxylase.

(A) A double reciplocal plot of $p_{\mathrm{m} a x}$ ys. $\mathrm{O}_{2}$ concentration. The holoenzyme solution with the substrate reduced with NADPH was mixed with an equal volume of the buffer solution containing different concentrations of oxygen. The absorbance changes at $600 \mathrm{~nm}$ were followed by the stoppedflow apparatus. The height of the peak in absorbance changes ( $p_{\max }$ : see Fig. 1-B) were plotted. Holoenzyme: $6.8 \mu \mathrm{M}$, NADPH: $475 \mu \mathrm{M}$, p-hydroxybenzoate: $286 \mu \mathrm{M}$, Oxygen: $65 \sim 500 \mu \mathrm{M}$ (final).

(B) A double reciplocal plot of $p_{\max }$ ws. substrate concentration. Only substrate concentration was varied. Holoenzyme: $6.8 \mu \mathrm{M}, \mathrm{NADPH}: 475 \mu \mathrm{M}$, Oxygen: $620 \mu \mathrm{M}$, p-hydroxybenzoate: $28.6 \sim 286 \mu \mathrm{M}$. 
$\therefore$ New Enzyme Species of $p$-Hydroxybenzoate Hydroxylase during Oxygenating Process Observed 1083

of absorbance changes $\left(p_{\mathrm{m}}\right)$ was clearly depended on the concentrations of both substrate and oxygen. And $p_{\mathrm{m}}$ was also depended on the enzyme concentration. These resuts indicate that the transient enzyme species at the presteady state of oxygenation step is a ternary complex of the enzyme, substrate and axygen, such as $\mathrm{E}_{\text {red }}-\mathrm{S}-\mathrm{O}_{2}$ which had previously been proposed as an intermediate by us."

Difference absorption spectra at two difinite times after the initiation of reaction were obtained and compared with each other (Fig. 3). The difference spectrum at $0.5 \mathrm{sec}$ after the initiation of reaction (Fig. 3, curve I) showed a weak and a broad absorption band at 500 $700 \mathrm{~nm}$. In anaerobic reduction of $p-\mathrm{HBA}$ hydroxylase the spectrum which indicates a flavin radical has not been detected." Thus it is preferable that the transient enzyme species at the presteady state of oxygenation step is a charge transfer complex among $\mathrm{FADH}_{2}$ moiety, $p$-HBA and oxygen.

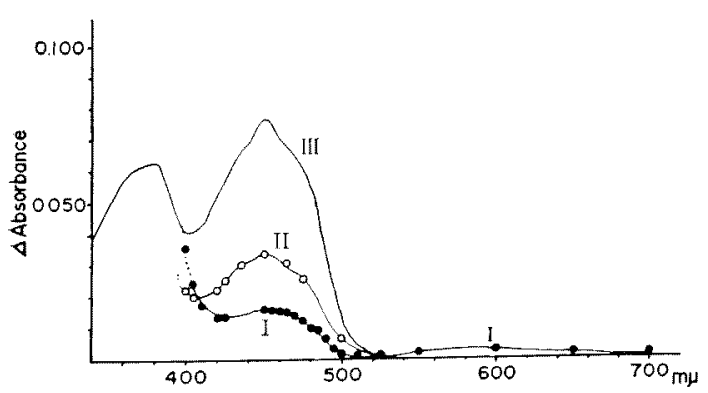

FIG. 3. Spectrophotometric Assignment of a New Enzyme Species of p-Hydroxybenzoate Hydroxylase during Oxygenation Process Observed by the Stopped-How Method.

From the stopped-flow traces at various wavelengths, difference spectra against the fully reduced enzyme were obtained at $500 \mathrm{msec}$ (presteady state in Fig. 1) and $3 \mathrm{sec}$ (steady state) after the initiation of reaction. 1: a difference spectrum of presteady state, II: a difference spectrum of steady state, III: a spectrum of the oxidative form of enzyme with substrate. Experimental conditions were the same as stated in the legend of Fig. 1.
An oxygenated intermediate is proposed as an important intermediate of oxygenase reac$\operatorname{tion}^{7,81}$ (iron containing dioxygenases). As to flavoprotein oxygenases, presence of the oxygenated complex was expected to be an intermediate of oxygenation, but it has not been detected practically. ${ }^{910}$ Very recently Yamamoto et al. have observed a new spectrum species during the steady state of oxygenation step of lysine monooxygenase. ${ }^{11}$ Oxygenation reaction needs the activation and cleavage of molecular oxygen, but the mechanism has not been clarified so for. An oxygenated intermediate plays an essential role in activation of molecular oxygen. Therefore, the precise investigations on the new transient enzyme species during the oxygenation step of $p$-hydroxybenzoate hydroxylase may provide us important clues for oxygenation reaction. The details will be presented elsewhere.

The authors wish to express their gratitude to Dr. Y. Ogura and Dr. H. Suzuki (Tokyo Univ.) and Dr. K. Hiromi (Kyoto Univ.) for the use of stopped-flow apparatus and for useful discussions. Thanks are also due to Dr. S. Nakamura (Wayne State Univ.), Dr. I. Yamazaki (Hokkaido Univ,), Dr. T. Nakamura (Osaka Univ.) and Dr. T. Beppu (Tokyo Univ.) for their valuable criticism in this work.

\section{REFERENCES}

1) K. Yano, N. Higashi and K. Arima, Biochem. Biophys. Res. Commun., 34, 1 (1969).

2) K. Yano, N. Higashi, S. Nakamura and $K$. Arima, ibid., 34, 277 (1969).

3) N. Higashi, H. Shoun, K. Hiromi, K. Iano and K. Arima, J. Biochem., 67, 749 (1970).

4) S. Nakamura, Y. Ogura, K. Yano, N. Higashi and K. Arima, Biochemistry, 9, 3235 (1970).

5) B. Chace and V. Legallais, Rev. Sci. Instr., 22, 627 (1951).

6) T. Nakamura and Y. Ogura, J. Biochem., 52, 214 (1962).

7) Y. Ishimura, M. Nozaki, O. Hayaishi, T. Nakamura, T. Tamura and 1. Tamazaki, J. Biol. Chem., 245, 3539 (1970).

8) H. Fujisawa, K. Hiromi, M. Ueda, M. Nozaki 
and O. Hayaishi, J. Biol. Chem., 246, 2320 (1971).

Naoki HIGASHI

9) M. Katagiri, B. N. Gunguili and I. C. Gunsalus, Hirofumi SHOUN ibid., 243, 3542 (1968).

10) S. Takemori, M. Nakamura, S. Suzuki, M. Katagiri and T. Nakamura, FEBS Letters, 6, 305 (1970).

11) S. Yamamoto, F. Hirata, T. Yamauchi, M. Nozaki, K. Hiromi and O. Hayaishi, J. Biol. Chem., 246, 5540 (1971). 